\title{
Natural environmental radioactivity and estimation of radiation exposure from saline soils
}

\author{
${ }^{1 *}$. Akhtar, ${ }^{2}$ M. Tufail and ${ }^{3}$ M. Ashraf \\ ${ }^{1}$ Health Physics Division, NIAB, Jhang Road, Faisalabad, Pakistan \\ ${ }^{2}$ Pakistan Institute of Engineering and Applied Sciences, Nilore, Islamabad, Pakistan \\ ${ }^{3}$ Department of Physics, Bahauddin Zakariya University, Multan, Pakistan
}

\begin{abstract}
The study was conducted for the investigation of amount of radioactivity in the barren and cultivated soil of Bio saline Research Station in Pakka Anna, established by Nuclear Institute for Agriculture and Biology (NIAB) in 1990, $34 \mathrm{~km}$. away from the city of Faisalabad, in the Punjab province of Pakistan. The studies were done on an area of about 100 hectares of two types of virgin and fertilized saline soils. The technique of gamma ray spectrometry was applied using HPGe (high purity germanium) gamma ray detector and a PC based MCA. Activity concentration levels due to ${ }^{40} \mathrm{~K},{ }^{137} \mathrm{Cs}$, ${ }^{226} \mathrm{Ra}$ and ${ }^{232} \mathrm{Th}$ were measured in 250 saline soil samples collected at a spacing of about 4 hectares at the depth level of $0-25 \mathrm{~cm}$. with a step of $5 \mathrm{~cm}$. depth. Activity concentrations ranges of the concerned radionuclides for both of the soils were as follows: ${ }^{40} \mathrm{~K}$, for virgin and cultivated saline soil was $500-610.2$ and $\mathrm{Bq} / \mathrm{kg}$ 560.2-635.6 respectively; ${ }^{137} \mathrm{Cs}$, 3.57-3.63 and $1.98-5.15 \mathrm{~Bq} / \mathrm{kg}{ }^{238} \mathrm{U}, 26.3-31.6$ and $30.3-38.7 \mathrm{~Bq} / \mathrm{kg}$, and ${ }^{232} \mathrm{Th}$, $50.6-55.3$ and 50.6-64.0 Bq/kg respectively. The absorbed dose rate in air lies in the region $63-73 \mathrm{nGyh}^{-1}$ and $68-83$ $\mathrm{nGyh}^{-1}$ for virgin and fertilized soils respectively. This indicates that this region lies in the area of higher radiation background, while comparing with the worlds' average. The slightly higher value of dose in the fertilized farm may be due to the use of fertilizers for cultivation. Before the radiometric measurements, chemical analysis for concentration of $\mathrm{Na}, \mathrm{Ca}$ and $\mathrm{Mg}$ was also carried out along with the measurement of electrical conductivity and $\mathrm{pH}$ of the soil samples.
\end{abstract}

Key Words: Saline soil, virgin soil, fertilized soil, HPGe detector, gamma spectrometry, environmental radioactivity, ${ }^{40} \mathrm{~K},{ }^{137} \mathrm{Cs},{ }^{226} \mathrm{Ra},{ }^{232} \mathrm{Th}$

*Corresponding Author, E-mail: nasimhpniab@yahoo.com

\section{Introduction}

There is a great interest in the study of natural environmental radiation and radioactivity in soil because the population is exposed to natural radioactivity at different levels depending on natural radioactive minerals in each region in the world (Radhakrishna, et al., 1993).

Naturally occurring radiation and environmental radioactivity has led to the performance of extensive surveys in many countries of the world (UNSCEAR, 2000). Such investigations can be useful for both the assessment of public dose rates and the performance of epidemiological studies, as well as to keep reference-data records, in order to ascertain possible changes in the environment radioactivity due to nuclear, industrial, and other human activities. Natural environmental radioactivity arises mainly from primordial radionuclides, such as ${ }^{40} \mathrm{~K}$ and the nuclides from the ${ }^{232} \mathrm{Th}$ and ${ }^{238} \mathrm{U}$ series and their decay products, which occur at trace levels in all ground formations. Primordial radionuclides are formed by the process of nucleo-synthesis in stars and are characterized by half-lives comparable to the age of the earth (Tzortzis, 2003).

Natural environmental radioactivity and the associated external exposure due to gamma radiation depend primarily on the geological and geographical conditions, and appear at different levels in the soils of each region in the world (UNSCEAR, 2000). The specific levels of terrestrial environmental radiation are related to the composition of each lithologically separated area, and to the content of the rock from which the soils originate. There are many types of soils depending upon the physical and chemical composition. The soil is classified as saline, saline sodic and alkali etc. (Brady, et al., 1990). In saline soil, the concentration of salts is increased to the level at which the crop growth is adversely affected. Saline soils have a high content of natural salts and have $\mathrm{pH}$ generally above 7.3 and not over 8.5. Nuclear fission in connection with atomic weap- 
ons testing provides another source of soil contamination.

Direct fall out from the atmosphere on the vegetation was primary source of contamination (IAEA, 1989). The fission product ${ }^{137} \mathrm{Cs}$ is strongly absorbed and retained by soil particles, as are the natural radio nuclides, which are found randomly, distributed at different depths of soil (Zahid, et al., 2001). The subject of radioactive contamination gained considerable public importance because of Chernobyl accident. Naturally occurring radio nuclides (uranium and thorium series, etc.) are the largest contributors to radiation doses received by human beings. Because of increased public concern and awareness about radioactive pollution, this study has been carried out to measure the amount of radioactivity and assessment of radiation dose from the saline soils of Faisalabad area.

\section{Materials and Methods}

\section{Study area}

The study was conducted on an area consisted of 80 hectares of saline soil in the Pakka Anna 34 $\mathrm{km}$ from the famous city of Faisalabad (called Manchester of Pakistan) in the Punjab province of Pakistan. The lactation of the area is $31^{\circ} 24^{\prime} \mathrm{N}$ and $73^{\circ} 05^{\prime} \mathrm{E}$ and at the elevation of $190 \mathrm{~m}$ from the sea level. The annual rainfall in this area is $310 \mathrm{~mm}$. The only source of irrigation is tube-wells having EC of $4.8 \mathrm{ds} / \mathrm{m}$; sodium absorption ratio (SAR) is equal to 39.5 and sodium carbonate (RSC) ranging $18-23$. The soil is medium texture with salinity ranging 21-6 desi semin/meter $(\mathrm{ds} / \mathrm{m})$ from $1 \mathrm{~m}$ depth of soil profile. Nuclear Institute of Agriculture and Biology (NIAB) in 1990 have established a Bio Saline Research Station No. 2 in this area.
The area was almost barren until 1989. Proper cultivation was started after the establishment of the saline research station in 1990.

\section{Soil sampling}

The field experiment was laid on 50 sites. The distance between each point (site) was about 15$17 \mathrm{~km}$. Soil sampling was done in the month of MayJune 2002, from two types of saline soils, one which has the soil where regular cultivation practices are going on since 1990 (named fertilized soil) and the other type which was never cultivated (named virgin soil). Sampling from the saline patches was performed using the Standard Sampling Methods (Brady, et al., 1990), at a step of $5 \mathrm{~cm}$ depth covering $25 \mathrm{~cm}$ depth for the both soils. In this way fifty points (sites) were covered and the total number of samples was 250 . The samples were properly marked, cataloged and brought to Health Physics Laboratory at NIAB, Faisalabad, Pakistan for processing before analysis.

\section{Laboratory tests}

Before performing the chemical analysis, electrical conductivity (EC) was measured with an $\mathrm{EC}$ meter and $\mathrm{pH}$ was measured with a $\mathrm{pH}$ meter. Titration method was used for the concentration of sodium and magnesium and flame photometer technique was applied for the analysis. The chemical analyses are shown in Table 1.

\section{Sample processing and packing}

The soil samples were first kept in the sun for several days. After crushing in small pieces, the samples were then dried in a temperature-controlled oven at $100^{\circ} \mathrm{C}$ for the time until the moisture of the soil was removed completely.

Table 1: Chemical analysis of soil samples of fertilized and virgin soils of Pakka Anna

\begin{tabular}{|cccccc|}
\hline $\begin{array}{c}\text { Soil } \\
\text { Samples }\end{array}$ & $\begin{array}{c}\text { Depth } \\
(\mathrm{cm})\end{array}$ & $\begin{array}{c}\text { Electrical Conductivity } \\
(\mathrm{EC}) \mu \mathrm{s} / \mathrm{cm}\end{array}$ & $\mathrm{pH}$ & $\begin{array}{c}\text { Concentration } \\
\text { of Ca+Mg } \\
(\mathrm{meq} / \mathrm{l})\end{array}$ & $\begin{array}{c}\text { Concentration } \\
\text { of Na (meq/l) }\end{array}$ \\
\hline F1 & $0-5$ & 4.38 & 7.80 & 1.0 & 89 \\
F2 & $5-10$ & 3.87 & 8.02 & 0.80 & 93 \\
F3 & $10-15$ & 3.01 & 8.21 & 0.60 & 78 \\
F4 & $15-20$ & 2.53 & 8.24 & 0.54 & 74 \\
F5 & $20-25$ & 3.17 & 8.32 & 0.44 & 82 \\
V1 & $0-5$ & 15.3 & 7.28 & 8.30 & 95 \\
V2 & $5-10$ & 7.15 & 7.50 & 7.90 & 76 \\
V3 & $10-15$ & 5.92 & 7.59 & 5.30 & 98 \\
V4 & $15-20$ & 4.50 & 7.64 & 2.50 & 91 \\
V5 & $20-25$ & 4.02 & 7.79 & 0.80 & 87 \\
\hline
\end{tabular}


The dried samples were ground, powdered and passed though a sieve of mesh size $200 \mu \mathrm{m}$. cylindrical plastic containers (Chemical resistant) were filled and packed with soil samples. The containers were thick enough for permeation of radon (Tufail, et al., 1992). The empty containers were weighed and were filled with soil samples and weighed again. The net weight of the soil was noted. The containers were closed by screw caps and plastic tapes were wrapped over the caps. Same procedure was applied for the reference material, (Soil-6 obtained from IAEA). The samples and standards were stored for more than 40 days to achieve secular equilibrium between ${ }^{222} \mathrm{Rn}$ and ${ }^{226} \mathrm{Ra}$ (Tufail, et al., 2000).

\section{Radiometric analysis}

The technique of gamma ray spectrometry was applied for determination of radioactivity of the samples under investigation. The spectrometry system consisted of an HPGe detector (model Ge3020) having active volume $180 \mathrm{~cm}^{3}$ with relative efficiency $30 \%$ and operating voltage $3000 \mathrm{~V}$. For acquisition of data and analysis, a multichannel analyzer (MCA) card of 8196 channels with inbuilt power supply, preamplifier and amplifier were installed in a personal computer (PC). The resolution of the system was $2 \mathrm{keV}$ at $1332.5 \mathrm{keV}$ peaks of ${ }^{60} \mathrm{Co}$. Spectrum of every soil sample was collected for 65,000 seconds. Areas under the peaks corresponding to the energies given in Table 2 were used for plotting the peak efficiency curve between log of efficiency versus log of peak energy. A polynomial was fitted to the curve and polynomial was stored in the PC for later reference for analyzing the spectra of the soil samples. The lowest limits of detection (LLD) were determined for ${ }^{40} \mathrm{~K}$, ${ }^{137} \mathrm{Cs},{ }^{232} \mathrm{Th}$ and ${ }^{238} \mathrm{U}$ and are given in Table 3. Spectrum analysis was done with help of the computer software Gene 2000, and activity concentration for ${ }^{40} \mathrm{~K},{ }^{137} \mathrm{Cs},{ }^{238} \mathrm{U}$ and ${ }^{232} \mathrm{Th}$ were determined.

\section{Results}

High-resolution spectrometry technique was employed for the measurement of gamma ray The average values of activity concentrations due to ${ }^{40} \mathrm{~K}$, ${ }^{238} \mathrm{U}$ and ${ }^{232} \mathrm{Th}$ for the virgin saline and fertilized saline samples were found to be within the range specified by UNSCEAR. The concentration of ${ }^{137} \mathrm{Cs}$ was so small to contribute the total radiation exposure.
Gamma absorbed dose rates in air outdoors were calculated and effective doses were estimated. The doses within the statistical error were same for both types of soils. There is a slightly increasing trend of radiation dose in air from the fertilized soil when compared with the virgin soil that may be due to

Table 2: Gamma ray energies used for calibration of spectrometer and for measurement of activity concentration of the radionuclides of interest

\begin{tabular}{|c|c|c|c|}
\hline $\begin{array}{c}\text { Parent } \\
\text { Nuclide }\end{array}$ & $\begin{array}{l}\text { Daughter } \\
\text { Nuclide }\end{array}$ & $\begin{array}{c}\gamma \text {-ray } \\
\text { Energy } \\
(\mathrm{keV})\end{array}$ & $\begin{array}{c}\text { Abundanc } \\
\text { e (\%) }\end{array}$ \\
\hline \multirow[t]{8}{*}{${ }^{226} \mathrm{Ra}$} & ${ }^{214} \mathrm{~Pb}$ & 241.98 & 7.12 \\
\hline & ${ }^{214} \mathrm{~Pb}$ & 395.21 & 19.20 \\
\hline & ${ }^{214} \mathrm{~Pb}$ & 351.92 & 35.10 \\
\hline & ${ }^{214} \mathrm{Bi}$ & 609.32 & 44.60 \\
\hline & ${ }^{214} \mathrm{Bi}$ & 768.30 & 4.76 \\
\hline & ${ }^{214} \mathrm{Bi}$ & 1120.28 & 14.70 \\
\hline & ${ }^{214} \mathrm{Bi}$ & 1238.11 & 5.78 \\
\hline & ${ }^{214} \mathrm{Bi}$ & 1764.52 & 15.10 \\
\hline \multirow[t]{11}{*}{${ }^{228} \mathrm{Th}$} & ${ }^{228} \mathrm{Ac}$ & 202.39 & 3.81 \\
\hline & ${ }^{212} \mathrm{~Pb}$ & 238.63 & 43.50 \\
\hline & ${ }^{228} \mathrm{Ac}$ & 338.42 & 11.26 \\
\hline & ${ }^{228} \mathrm{Ac}$ & 463.10 & 4.50 \\
\hline & ${ }^{208} \mathrm{Tl}$ & 583.19 & 30.58 \\
\hline & ${ }^{212} \mathrm{Bi}$ & 727.33 & 6.64 \\
\hline & ${ }^{208} \mathrm{Tl}$ & 860.56 & 4.50 \\
\hline & ${ }^{228} \mathrm{Ac}$ & 911.16 & 26.60 \\
\hline & ${ }^{228} \mathrm{Ac}$ & 964.64 & 5.05 \\
\hline & ${ }^{228} \mathrm{Ac}$ & 968.97 & 16.23 \\
\hline & ${ }^{208} \mathrm{Te}$ & 2641.60 & 35.80 \\
\hline${ }^{40} \mathrm{~K}$ & & 1460.80 & 10.67 \\
\hline${ }^{137} \mathrm{Cs}$ & & 660.00 & 87.02 \\
\hline
\end{tabular}

Table 3: The lowest limit of detection (LLD) for the radionuclides; ${ }^{40} \mathrm{~K},{ }^{137} \mathrm{Cs},{ }^{226} \mathrm{Ra}$ and ${ }^{232} \mathrm{Th}$

\begin{tabular}{|c|c|}
\hline Nuclide & $\begin{array}{c}\text { Lowest Detection Limit } \\
\left(\mathrm{Bq}^{\mathrm{kg}}{ }^{-1}\right)\end{array}$ \\
\hline${ }^{40} \mathrm{~K}$ & 59 \\
${ }^{137} \mathrm{Cs}$ & 1.3 \\
${ }^{226} \mathrm{Ra}$ & 3.3 \\
${ }^{232} \mathrm{Th}$ & 3.3 \\
\hline
\end{tabular}


present of radioactivity in the fertilizers. The values of the estimated dose rates, when compared with the radiation dose rates given in the UNSEAR report, are observed to be lying within the ranges of the report.

\section{Discussion and Conclusion}

The results of this investigation for the soil samples from saline patches of Pakka Anna near the city of Faisalabad in the Punjab province of Pakistan are summarized in Table 4 . The three most common primordial radionuclides investigated in the study area were ${ }^{40} \mathrm{~K},{ }^{226} \mathrm{Ra}$ and ${ }^{232} \mathrm{Th}$. The tabulated activity for the naturally occurring radionuclides ${ }^{226} \mathrm{Ra}$ and ${ }^{232} \mathrm{Th}$ is the average of the activities of most abundant photo peaks of the decay products of the uranium and thorium series given in Table 2 . The activity concentrations of natural ${ }^{40} \mathrm{~K}$ and the fission product ${ }^{137} \mathrm{Cs}$ are single peak results. No variation of the measured activity was observed with respect to the sample depth, therefore the activity measured at one location was averaged out and the mean values are only tabulated.

Natural potassium has 3 isotopes: ${ }^{39} \mathrm{~K},{ }^{40} \mathrm{~K}$ and ${ }^{41} \mathrm{~K}$. Among them only ${ }^{40} \mathrm{~K}\left(\mathrm{~T}_{1 / 2}=1.3 \times 10^{9} \mathrm{y}\right)$ possesses natural gamma radioactivity and its abundance in nature is $0.012 \%$ of all potassium present in the earth crust. During decay ${ }^{40} \mathrm{~K}$ produces two daughter isotopes; ${ }^{40} \mathrm{Ca}$ and ${ }^{40} \mathrm{Ar}$, with the emission of beta and gamma radiation. The average value of concentration along with range of ${ }^{40} \mathrm{~K}$ in the virgin soil was $555 \mathrm{~Bq} \cdot \mathrm{kg}^{-1}$ and that in the fertilized soil was 597 Bq. $\mathrm{kg}^{-1}$.

The other naturally occurring radionuclides in addition to potassium measured, were ${ }^{226} \mathrm{Ra}$ and ${ }^{232} \mathrm{Th}$. Radium-226 (a member of ${ }^{238} \mathrm{U}$ series) is considered as the highly radiotoxic natural radionuclide. The average value and range of measured concentration of ${ }^{238} \mathrm{U}$ for virgin soils was $29 \mathrm{~Bq} \cdot \mathrm{kg}^{-1}$ and that for the fertilized soil was 34 Bq.kg ${ }^{-1}$. For ${ }^{232} \mathrm{Th}\left(\mathrm{T}_{1 / 2}=1.4 \times 10^{10} \mathrm{y}\right)$, the average value and range of measured specific activity for both types of soils; virgin and fertilized were 53 Bq. $\mathrm{kg}^{-1}$ and 57Bkg1 respectively. The ratio of ${ }^{232} \mathrm{Th}$ to ${ }^{226} \mathrm{Ra}$ in the earth's crust is generally greater than one and that is also true for the present case. The average activity value of ${ }^{232} \mathrm{Th}$ was about two times higher than that of ${ }^{238} \mathrm{U}$ The activity concentration of ${ }^{40} \mathrm{~K}$ in soil is order of magnitude higher than that of ${ }^{238}$ Uand ${ }^{232} \mathrm{Th}$ for the both types of the soils. This is also in accordance with the well-known fact that potassium in the earth's crust is of the order of percentage whereas uranium and thorium are in ppm level. The average value of activity concentration of ${ }^{137} \mathrm{Cs}$ in all the samples found in virgin and fertilized soils of Pakka Anna, was 3.6 Bq. $\mathrm{kg}^{-1}$ and $4.15 \mathrm{~Bq} \cdot \mathrm{kg}^{-1}$ respectively. In most of the virgin soil samples, the activity concentration of ${ }^{137} \mathrm{Cs}$ was below the lowest limit of detection (LLD). The reasons of less existence of ${ }^{137} \mathrm{Cs}$ in the barren saline soils of Pakka Anna are that the trees and grass in the land might have reduced the amount of ${ }^{137} \mathrm{Cs}$ from the land. The less values of fall out may be due to erosion of ${ }^{137} \mathrm{Cs}$ by rain from the area (Akhtar, et al., 2003) the winds, cattle grazing, etc. may be the some other reason for the reduced values in the area of interest. The variations in the activity levels have been observed to be lying within the activity values measured all over the world (IAEA1, 1989 and UNSEAR, 2000). The comparison of activity levels with that of the world level can be observed from Table 5. According to UNSCAR report (2000), the world average value of activity concentration for ${ }^{40} \mathrm{~K}$ is $140-850 \mathrm{~Bq} \cdot \mathrm{kg}^{-1}$. The measured value of activity concentration of ${ }^{40} \mathrm{~K}$ for the area under investigation for both categories of soil, virgin and fertilized, was within the world average range. The ranges of activity concentrations for ${ }^{238} \mathrm{U}$ and ${ }^{232} \mathrm{Th}$ given in the UNSCAR report are 1760 and 11-64 Bq. $\mathrm{kg}^{-1}$ respectively. The measured values of the activity concentration for the samples from Pakka Aana, Faisalabad was also lying within the world averages. As far as the mutual comparison of the virgin and fertilized soils of the area under investigation is concerned, there is no drastic change in the activity concentrations in both types of soils. However, a slight increasing trend was observed in the measured activity of fertilizes soil. It is well known that the phosphate rocks contain substantial concentration of uranium, thorium, radium and radium decay products (Skorovarov, et al., 1996). Since phosphate rock is an essential raw material used for the manufacturing of different type's phosphatic fertilizers, therefore, when this rock is processed into phosphatic fertilizers, most of the uranium and some of the radium accompanies the fertilizers (Hussain, et al., 1994). It has also been estimated earlier that phosphatic fertilizers applied to the fields in recommended amounts could raise radioactivity level in soils. The use of fertilizers in large extent have affected radionuclides concentration, especially potassium containing fertilizers are the one of the cause of presence of high activity of ${ }^{40} \mathrm{~K}$ in soil (Bhatti, et al., 1994). 
Table 4: Activity of naturally occurring radioisotopes in the samples from saline fertilized soil of Pakka Anna

\begin{tabular}{|c|c|c|c|c|c|c|}
\hline \multirow{2}{*}{$\begin{array}{l}\text { Sample } \\
\text { Name }\end{array}$} & \multirow{2}{*}{$\begin{array}{l}\text { Depth from } \\
\text { Land Surface } \\
\text { (cm.) }\end{array}$} & \multirow{2}{*}{$\begin{array}{c}\text { No. of } \\
\text { Samples }\end{array}$} & \multicolumn{4}{|c|}{ Activity Concentration (Bq/kg) } \\
\hline & & & ${ }^{40} \mathrm{~K}$ & ${ }^{232} \mathrm{Th}$ & ${ }^{238} \mathrm{U}$ & ${ }^{\mathrm{I} 37} \mathrm{Cs}$ \\
\hline \multicolumn{7}{|c|}{ Virgin Saline Soil } \\
\hline $\mathrm{V}-1$ & $0-5$ & 25 & $557.8 \pm 21.5$ & $53.3 \pm 1.9$ & $24.29+2.11$ & $3.57 \pm 0.45$ \\
\hline $\mathrm{V}-2$ & $5-10$ & 25 & $449.2 \pm 21.8$ & $48.5 \pm 2.0$ & $26.07 \pm 1.3$ & $3.6+0.44$ \\
\hline $\mathrm{V}-3$ & $10-15$ & 25 & $542.7 \pm 21.4$ & $54.3 \pm 2.0$ & $25.56 \pm 1.2$ & Below LLD \\
\hline $\mathrm{V}-4$ & $15-20$ & 25 & $596.5 \pm 21.8$ & $53.7 \pm 2.0$ & $25.31 \pm 1.2$ & Below LLD \\
\hline $\mathrm{V}-5$ & $20-25$ & 25 & $604.2 \pm 21.5$ & $53.6 \pm 1.9$ & $28.61 \pm 1.2$ & Below LLD \\
\hline \multicolumn{7}{|c|}{ Fertilized Saline Soil } \\
\hline $\mathrm{F}-1$ & $0-5$ & 25 & $583.7 \pm 21.5$ & $62.3 \pm 2.2$ & $32.6 \pm 1.3$ & $5.0 \pm 0.4$ \\
\hline $\mathrm{F}-2$ & $5-10$ & 25 & $630.2 \pm 22.0$ & $55.8 \pm 2.1$ & $34.0 \pm 1.3$ & $4.5+0.4$ \\
\hline F-3 & $10-15$ & 25 & $619.5 \pm 21.9$ & $63.9 \pm 2.2$ & $32.4+4.3$ & $5.1 \pm 0.4$ \\
\hline $\mathrm{F}-4$ & $15-20$ & 25 & $621.8 \pm 21.9$ & $50.6 \pm 2.0$ & $35.0 \pm 1.3$ & $4.0 \pm 0.4$ \\
\hline F-5 & $20-25$ & 25 & $569.6 \pm 21.6$ & $58.3 \pm 2.1$ & $29.3 \pm 1.2$ & $1.9 \pm 0.4$ \\
\hline
\end{tabular}

In the study area the use of fertilizers started after the establishment of the Saline Research Centre in 1990 where the barren soil is being converted to cultivated soil. The soil is passing through many experiments with the extensive use of fertilizers. The slightly increasing trend at the beginning may be an indication of the large change of activity in the future due to the applications of fertilizers.

The decay of naturally occurring radionuclides in soil produces exposures to humans. External exposures outdoors arise from terrestrial radionuclides present at trace levels in all soils. The external gamma dose rate in air is calculated from measurement of concentration of the relevant radionuclide in soil. For uniformly distributed radionuclides, dose rate at $1 \mathrm{~m}$ above the ground surface can be calculated by using the following relation

$D=A_{C} \times C_{F}$

were, ' $\mathrm{D}$ ' is the dose rate in $n G y \cdot h^{-1}$, ' $\mathrm{A}_{\mathrm{c}}$ ' is the activity concentration in $B q \cdot \mathrm{kg}^{-1}$, and ' $\mathrm{C}_{\mathrm{F}}$ ' is the dose conversion factor in units of $n G y \cdot h^{-1}$ per Bq. $\mathrm{kg}^{-1}$ (absorbed dose rate in air per unit of activity concentration). The dose conversion factors shown in Table 5 were taken from the UNSEAR (2000) report, which are based on the Monte Carlo technique.

Table 5: Comparison of radioactivity concentration levels in the fertilized and virgin saline soils of Pakka Anna, Faisalabad, Pakistan with that of the world average

\begin{tabular}{|c|c|c|c|}
\hline \multirow[b]{2}{*}{ Radionuclide } & \multicolumn{3}{|c|}{$\begin{array}{l}\text { Activity Concentration } \\
\left.\text { (Bq. } \mathrm{kg}^{-1}\right)\end{array}$} \\
\hline & $\begin{array}{l}\text { Virgin } \\
\text { Soil }\end{array}$ & $\begin{array}{l}\text { Fertilized } \\
\text { Soil }\end{array}$ & $\begin{array}{c}\text { World Median } \\
\text { Range } \\
\text { (UNSCEAR, 2000) }\end{array}$ \\
\hline${ }^{40} \mathrm{~K}$ & $500-610$ & 560-635 & $140-850$ \\
\hline${ }^{238} \mathrm{U}$ & $26-31$ & $30-38$ & $17-60$ \\
\hline${ }^{232} \mathrm{Th}$ & $50--55$ & $50-64$ & $11-64$ \\
\hline
\end{tabular}


Table 6: Comparison of radiation absorbed dose in air due to natural radioactivity in the fertilized and virgin saline soils of Pakka Anna, Faisalabad,

Pakistan with that of world average

\begin{tabular}{|c|c|c|c|}
\hline \multirow{2}{*}{ Radionuclide } & \multirow{2}{*}{$\begin{array}{c}\text { Conversion } \\
\text { Factors }\end{array}$} & \multicolumn{2}{|c|}{$\begin{array}{c}\text { Absorbed dose } \\
\text { in air }\left(\mathrm{nGy} \mathrm{h}^{-1}\right)\end{array}$} \\
\cline { 3 - 4 } & $\begin{array}{c}\text { Virgin } \\
\text { Soil }\end{array}$ & $\begin{array}{c}\text { Fertilized } \\
\text { Soil }\end{array}$ \\
\hline${ }^{40} \mathrm{~K}$ & 0.0417 & $20.8-25.4$ & $23.5-26.3$ \\
${ }^{238} \mathrm{U}$ & 0.462 & $12.0-14.3$ & $13.8-17.5$ \\
${ }^{232} \mathrm{Th}$ & 0.604 & $30.2-33.2$ & $30.2-39.2$ \\
\multicolumn{2}{c}{ Total } & $63-73$ & $68-83$ \\
\multirow{2}{*}{$\begin{array}{l}\text { World median range } \\
\text { (UNSCEAR, 2000) }\end{array}$} & \multicolumn{2}{c}{$18-93$} \\
\hline
\end{tabular}

The gamma absorbed dose rates in air outdoor were estimated from the concentrations of each of the nuclides of ${ }^{238} \mathrm{U}$ (assuming that ${ }^{226} \mathrm{Ra}$ in secular equilibrium with ${ }^{238} \mathrm{U}$ ) and ${ }^{232} \mathrm{Th}$ series, and of ${ }^{40} \mathrm{~K}$ using equation 1 , and the individual results were added in order to obtain the total absorbed dose rate in air due to gamma radiation from those radionuclids. Figure 1 and Figure 2 show the estimated total gamma absorbed dose in air outdoors due to the ${ }^{40} \mathrm{~K},{ }^{238} \mathrm{U}$ and ${ }^{232} \mathrm{Th}$ radionuclids respectively in the virgin and fertilized soils of the area under investigation. The estimated dose rates vary from 63 to $73 \mathrm{nGy} \cdot \mathrm{h}^{1}$ with an average value of $66 \mathrm{nGy} \cdot \mathrm{h}^{1}$ for the virgin saline soil of the area whereas for the fertilized saline soil the estimated values of the dose rates vary from 64 to $79 \mathrm{nGyh}^{1}$ with an average value of $71.5 \mathrm{nGy} \cdot \mathrm{h}^{-1}$. There is no vast variation of the minimum and maximum values from the mean values, which indicates that radiation dose almost uniform throughout the saline patches of Pakka Aana of Faisalabad.

For an adult person, the dose rates were converted to effective dose rates by using the following relation (UNSEAR, 2000):

$H_{E}=D \times T \times F$

where, ' $\mathrm{H}_{\mathrm{E}}$ ' is the effective dose (in $\mu S y \cdot y^{-1}$ ), ' $\mathrm{D}$ ' is the estimated dose rate (in $n G y \cdot h^{-1}$ ), ' $T$ ' is the outdoor occupancy time factor $(0.2 \times 24 \times 365.25 d \cong 1753$ $h y^{-1}$ ), and ' $\mathrm{F}$ ' is the absorbed-to-effective dose conversion factor $\left(0.7 \times 10^{-3} \mu S v\right.$ per $\left.n G y\right)$. The effective dose rates outdoors environment was estimated according to equation 2. Soil samples of saline area were $82 \mu \mathrm{Sv} . \mathrm{y}^{-1}$ and $90 \mu \mathrm{Sv} \mathrm{y}^{-1}$ respectively for the virgin saline soil and the fertilized saline soil samples. The worldwide annual effective dose is within $0.3-0.6 \mathrm{mSv}$ range with an average value of $0.48 \mathrm{mSv}$. For children and infants, the values are about $10 \%$ and $30 \%$ higher, in direct proportion to an increase in the value of the conversion coefficient from absorbed dose in air to effective dose (UNSCEAR, 2000). The values of the dose rates estimated for the saline soils in the study are far below that of UNSCEAR values.

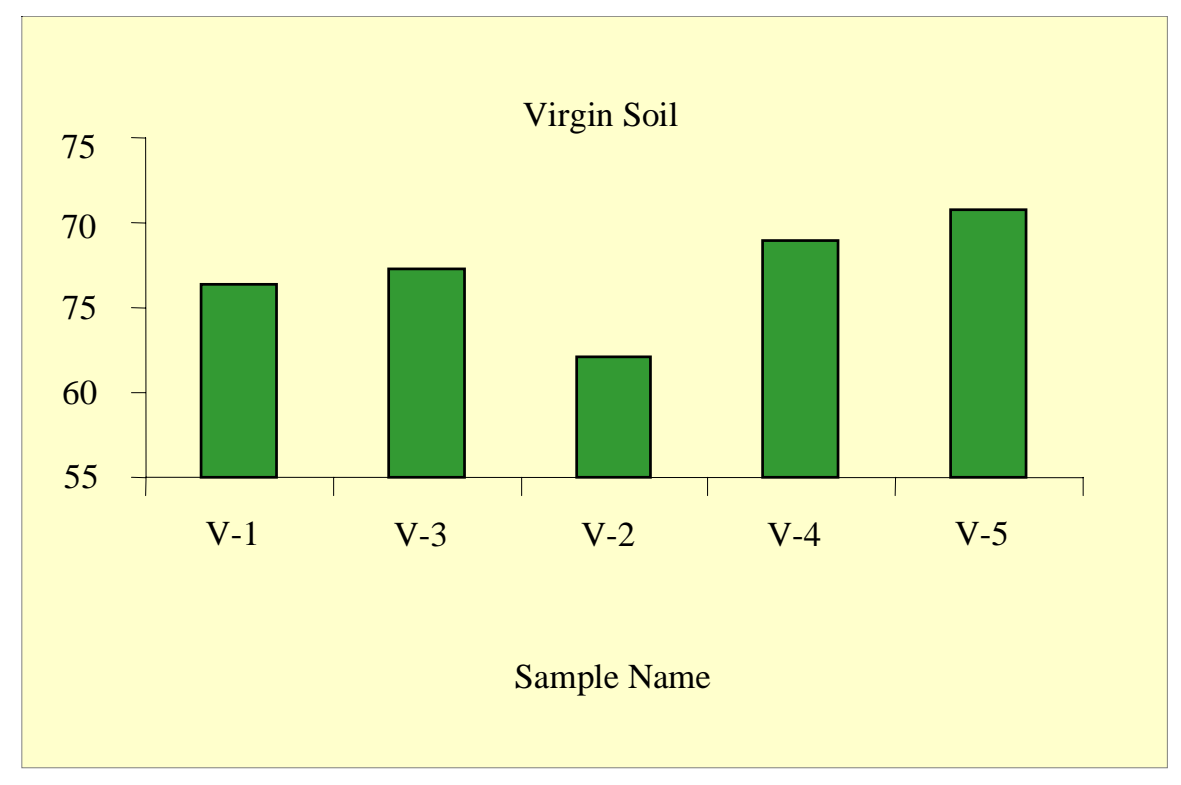

Figure 1: Absorbed dose rates in air due to gamma radiation from the virgin saline soil of Pakka Anna, Faisalabad, Pakistan 


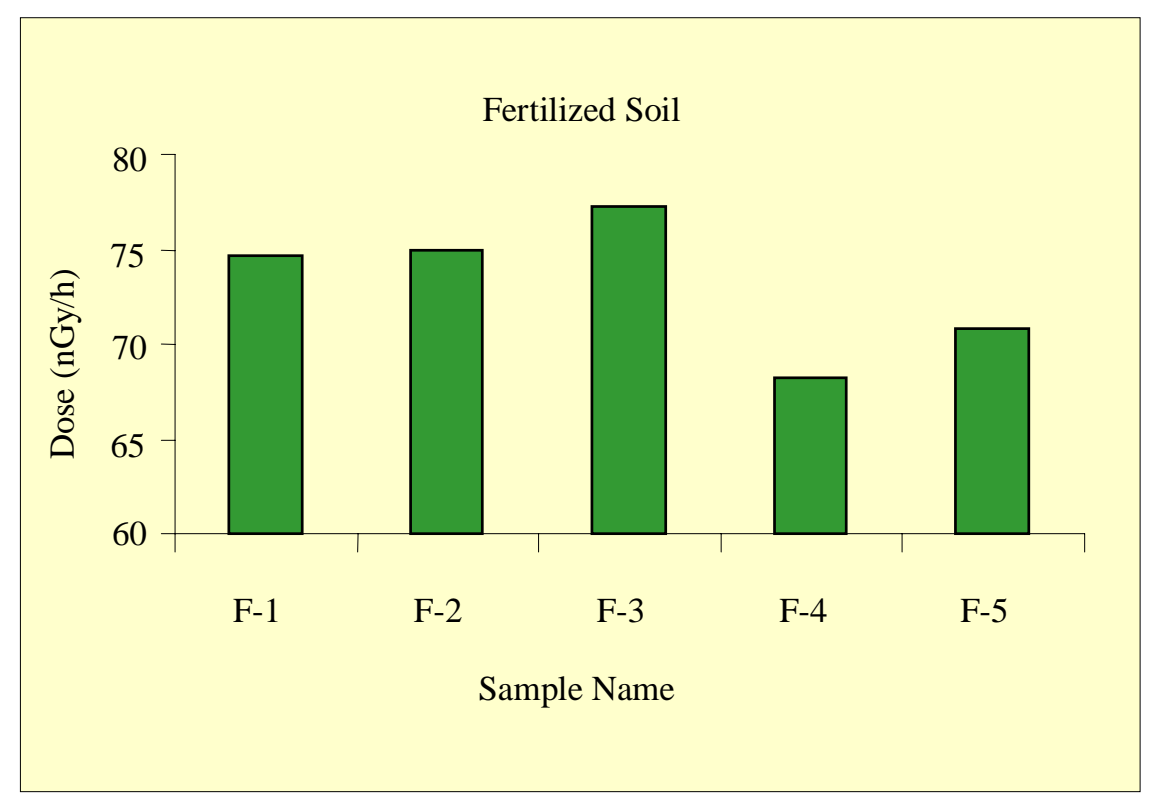

Figure 2: Absorbed dose rates in air due to gamma radiation from the fertilized saline soil of Pakka Anna, Faisalabad, Pakistan

\section{Acknowledgment}

The authors are thankful to Dr. S.S.Alam for kind reviewing of the manuscript and providing valuable comments.

\section{References}

Bhatti, T. M., Phosphate fertilizers a potential source for Uranium recovery as by product. A technical report no Paec/NIBGE-2/1994. National institute for biotechnology and genetic engineering (NIBGE), Faisalabad, 1994

Brady, N. C., the nature and properties of soils, $10^{\text {th. }}$ Ed., Macmillan Publisher London, 243-246, 1990

Hussain, A., Determination of uranium and thorium concentration in rock samples. J. of radio analytical and Nuclear physics, 188 (4): 255-265, 1994

IAEA, Measurement of radionuclides in food and environment. Technical reports series, (295), 1989

Akhtar, N., M. Ashraf Chaudhry, M. Tifail, M. Mohsin Iqbal and S. D. Orfi, Radiometric and chemical analysis of saline soil samples of Pacca Anna, Faisalabad, J. of Research, 14(1): 49-59, 2003

Radhakrishna, A.P., H. M. Somashekarappa, Y. Narayana, K. Sidappa, A new natural background radiation area on the southwest cost of India. Health Physics 65: 390-395, 1993
Selvasekarapandia, S., R.Sivakumar, N.M. Manikendan, V. Meenakshisundaram and V. Gajendran, Natural radionuclides distribution in soils of Gudalore India. Applied radiation and isotopes 52(2): 299-306, 2000

Skorovarov, J. I., L. I. Rusin, A. V. Lomonsov, H. Chaforian, A. Hashemi and H. Novaseqhi, . Development of uranium extraction technology from phosphoric acid solutions with extract. Proceeding of international conference on uranium extraction from soil, 217: 106-113, 1996

Tufail, M., M. Iqbal and S. M. Mirza, Radiation doses due to natural radioactivity in Pakistan marble; Radioprotection, 34: 355-359, 2000

Tufail, M., S. Almakky, M. S. Zafar, and H. A. Khan, Natural radioactivity in the ceramics used in dwellings as construction material, Scien. Total Environ, 127: 243-253, 1992

Tzortzis, M., H. Tsertos, S. Christofides, G. Christodoulides, Gamma ray measurements of naturally occurring radioactive samples from Cyprus characteristic geological rocks. Radiation Measurements 37: 221-229, 2003 